\title{
Total Hip Arthroplasty as a Salvage Procedure for Failed Traumatic Hips
}

\author{
Kedar Prashant Padhye ${ }^{1 *}$, MayurPatil², Sunil Kulkarni $^{2}$ and Milind Kulkarni ${ }^{2}$ \\ ${ }^{1}$ IWK Health Centre, Canada \\ ${ }^{2}$ Postgraduate Institute of Swasthiyog Pratishthan, India
}

Submission: October 31, 2017; Published: November 21, 2017

*Corresponding author: Kedar Prashant Padhye, IWK Health Centre, 5980 University Ave, Halifax, Nova Scotia, B3K 6R8 Canada, Tel: +1-902-210-2016; Email: kedarorth@gmail.com

\begin{abstract}
Background: The failed treatment of acetabulum, neck femur and intertrochanteric femur ultimately leads to either non-union or malunion or osteoarthritis of the hip. The operative treatment options for these failed hips are either resection or valgus osteotomy or salvage hip Arthroplasty [1-6]. The purpose of this study is to evaluate the functional outcomes, technical problems, and complications associated with total hip arthroplasty as a salvage procedure for failed hips.
\end{abstract}

Method: This retrospective study includes 30 patients who underwent total hip arthroplasty between 2005 to 2010, who had a failed hip in the form of nonunion, mal-union, implant failure or osteoarthritis secondary to conservatively treated fracture neck femur, acetabulum fracture, and intertrochanteric femur fracture. Preoperative and postoperative Harris Hip Score was used to compare functional outcomes. Paired t-test of significance was used for analysis.

Results: Seventeen males and 13 females with mean preoperative Harris hip score of 37.32 and 75.74 at 6 months postoperative. There was statistically significant $(\mathrm{p}<.05)$ increase in the functional outcome of treatment, with decreased hip pain on weight bearing, gain in walking distance, doing daily activities like climbing staircase, gain in the range of motion.

Conclusion: In conclusion, despite being a technically demanding nature of the procedure, salvage total hip arthroplasty is an effective reconstruction option for failed treatment of proximal femur fractures. The problems associated include difficult exposure, difficult cement pressurization due to leakage through the holes, stem subsidence, increased risk of postoperative infection, peri-prosthetic fractures, increased risk of dislocation, wound-related complications.

Keywords: Internal fixation failure; Intertrochanteric fracture; Non-modular stem; Nonunion; Total Hip Arthroplasty

\section{Introduction}

Most intertrochanteric hip fractures can be treated successfully with internal fixation [7]. Nevertheless, in a small percentage of patients, the fracture fails to heal because of the initial fracture pattern, comminution, suboptimal fracture fixation, or poor bone quality [8,9]. Although union rates as high as $100 \%$ have been reported in association with well-reduced, stable fractures that were treated with ideal implant placement, failure rates of as high as $56 \%$ have been noted with certain problematic fracture patterns or due to inappropriate fixation $[8,10]$. Similar is the case with fracture neck of femur in which failure of blood supply can lead to a vascular necrosis of femoral head.

Acetabular fractures are associated with damage to the femoral head and acetabular cartilage, labral injuries, and possible disruption of the femoral head blood supply. It can lead on to potentially irreparable complications like post-traumatic arthritis and femoral head osteonecrosis [11,12]. These failed treatments ultimately lead to non-union, mal-union or osteoarthritis of the hip. Apart from a non-operative treatment for very infirm patients, the main treatment options for these failed hips are either resection or valgus osteotomy or salvage hip Arthroplasty [1-6]. The purpose of this study is to evaluate the functional outcomes, technical problems, and complications associated with total hip arthroplasty as a salvage procedure for failed hips.

\section{Materials and Methods}

This is a retrospective analysis conducted after the approval of institutional review board by identifying cases of total hip arthroplasty done between the periods of 2005 to 2011. The inclusion criteria for the study was

i. Age $>18$ years 
ii. Patients who underwent non-operative or operative treatment for either fracture neck of femur or intertrochanteric femur fracture or acetabulum fracture

iii. Treatment failure due to either non-union, mal-union, implant failure, screw back out, or osteoarthritis of the hip

iv. Patients who underwent total hip arthroplasty as a salvage treatment) minimum follow-up of 6 months. Those not fitting the inclusion criteria were excluded from the study.

From the computerized database of the institute, we identified 30 patients ( 17 male and 13 female) with a mean age of 49 years (range 36 to 60years).
Informed consent was obtained on from all individual participants included in the study. Out of 30 cases, 18 cases were of fracture neck femur, 5 patients had intertrochanteric femur fracture and 7 had acetabulum fracture. Of the 18 cases of neck femur fracture, 3 underwent conservative treatment, 8 had Austin Moore prosthesis, 3 had compression screws, and 4 had a dynamic hip screw. Of the 5 cases with an intertrochanteric femur fracture, 2 underwent non-operative management, and 3 had a dynamic hip screw. Of the 7 cases were acetabulum fracture, 2 had reconstruction plates and 5 underwent nonoperative management. Preoperatively each case was analyzed clinically with pain severity, range of motion testing, and the limit of ambulation and true limb length discrepancy as per the standard protocol for the hospital.

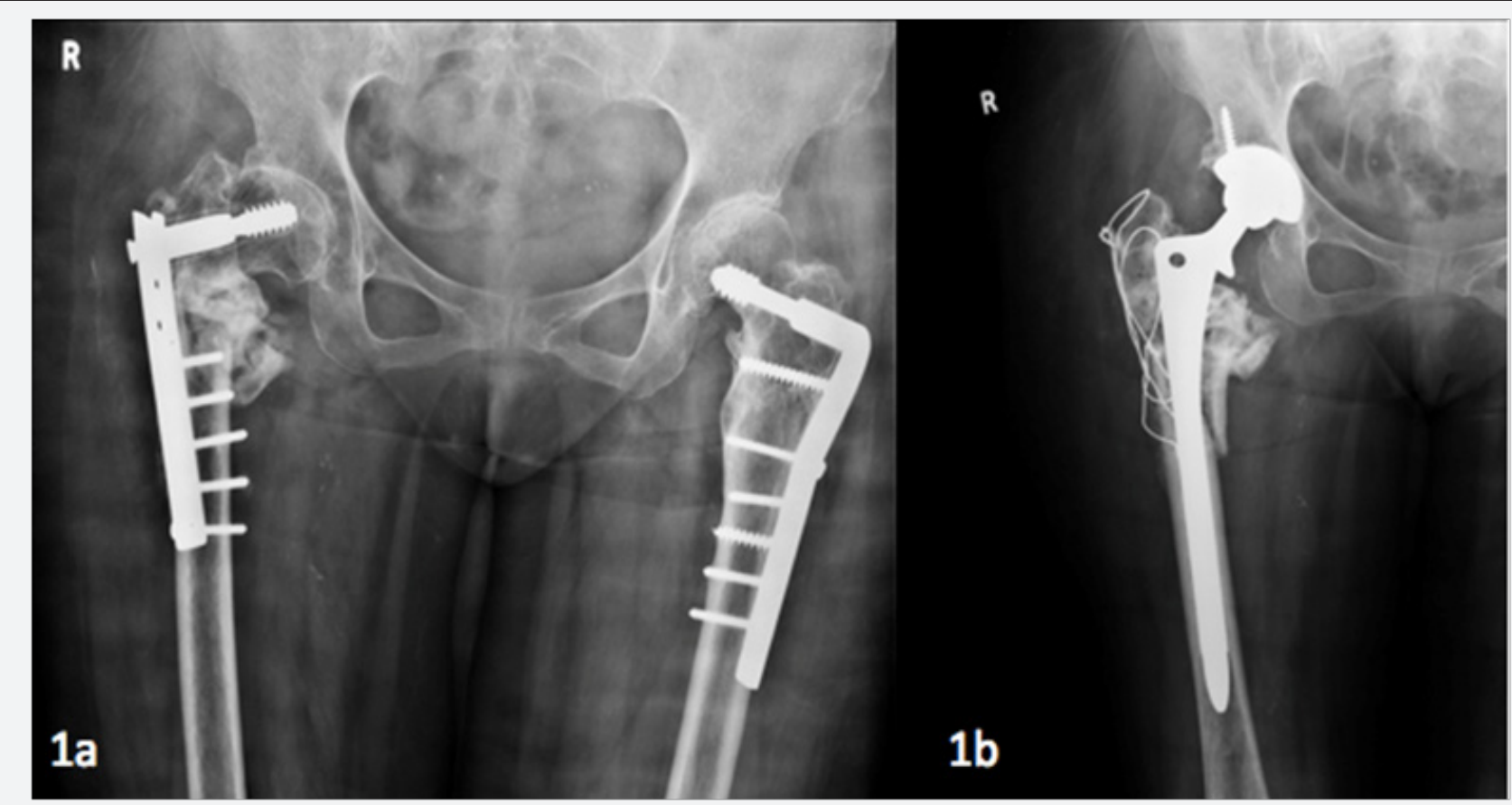

Figure 1:

a. Antero-posterior radiograph showing failed internal fixation with an osteoporotic bone on the right side.

b. Post-operative radiograph with total hip arthroplasty with tension band wire for greater trochanter.

Photographs with maximum possible range of motion at hip and walking videos of patient who could walk were taken. Templates were used to find out the appropriate size of the implants. Radiographs were studied and cause for failure was analyzed and templating was done. All cases were operated from posterolateral approach. Calcar resting design was used in all the 30 cases. Cement-less femoral component was used in 12 cases and cemented femoral component was used in 18 cases. A single acetabular screw was used in 20 cases for added stability mainly in osteoporotic patients. Implants were chosen considering patient's age, the quality of bone and surgeon's clinical judgment (Figure 1).

During the surgery, minimum of $5 \mathrm{~cm}$ gap was left between the new incision and the old scar when using a different approach. Technical difficulties faced during surgery were difficult dissection due to excess fibrous tissue in previously operated cases and difficulty in removal of the previous implant. Careful reaming of the acetabulum was done in cases of old acetabulum fracture. The previous implant used for acetabulum fracture was not removed in 1 case. Standard post-operative regimen for antibiotics and wound care was followed.

All patients were followed up every month for initial 6 months and every 6 months thereafter. The average follow-up was 14 months (range 12 to 36 months). At each follow-up, each patient was analyzed clinically and radiographically. Clinically, pain, local wound examination, range of motion examination was done. Radiographs were used to assess implant position, osteopenia around the implant and peri-prosthetic fracture. 
At the 6th month of follow-up each patient was given a questionnaire and patients all clinical parameters were noted down. Harris hip scores were used comparing preoperative and postoperative outcomes [13]. A paired t-test of significance was used to compare the data utilizing IBM SPSS Statistics version 23 (IBM Corporation; Armonk, New York).

\section{Results}

Thirty patients (17 male and 13 female) with a mean age of 49 years (range 36 to 60 years) were included in the study. Out of 30 cases, 18 cases were of fracture neck femur, 5 patients had intertrochanteric femur fracture and 7 had acetabulum fracture. The mean preoperative Harris hip score was 37.32 and mean postoperative score at 6 months' follow-up was 75.74. 17 cases $(56 \%)$ cases had a fair outcome (scores 70-79), 9 cases (30\%) had good outcome (scores $80-89$ ) and 4 cases (14\%) had poor outcome (scores $<70$ ). There was a statistically significant improvement in the post-operative functional outcomes compared to the preoperative outcomes $(\mathrm{p}<.001)$. Before the salvage hip arthroplasty, all patients had moderate to severe pain in the hip with passive range of motion.

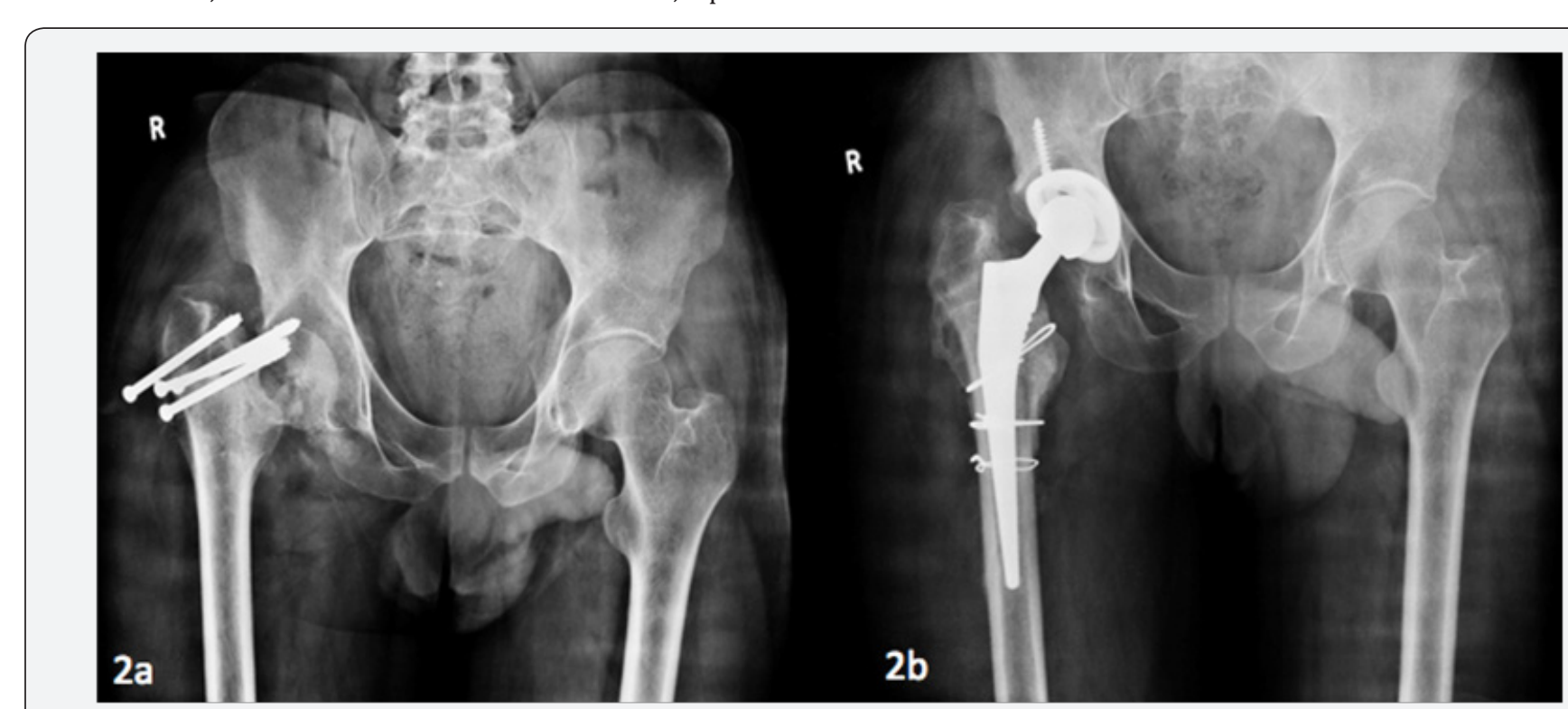

Figure 2:

a. Antero-posterior radiograph showing failed fixation for neck femur fracture with cutting out of compression screws.

b. Antero-posterior radiograph showing cement-less total hip arthroplasty with 3 cerclage cable for (Vancouver type A) peri-prosthetic fracture at 6 months follow up.

Out of the 30 patients, 26 were able to walk with support with while 4 were unable to walk. At the end of 1year, 27 (90\%) of 30 patients had no pain or mild pain and 3 had moderate to severe pain. $28(93 \%)$ of 30 patients were able to walk without support. 27 (90\%) patients were able to climb staircase with or without support. Complications included 2 cases of superficial wound infection which resolved with intravenous antibiotics. 1 patient developed peri-prosthetic fracture (Vancouver type A) and was re-operated with 3 cerclage cables were used (Figure 2).

\section{Discussion}

Pain and limited ambulatory capacity are the most common difficulties faced by patients with failed hips. Hip arthroplasty has been reported as one of the best salvage procedure for the treatment of failed hips in the literature [1-4,14-23]. A recent systematic review suggests that patients may obtain a similar functional outcome to primary THA if they opt for fixation first and subsequent failure requires revision to salvage THA [14]. However, failed initial treatment may have a major psychological impact on patients [14,24]. Failed hips present difficult and unique challenges to the orthopedic surgeons. The problems associated with salvage arthroplasty include difficult exposure, difficulty during cement pressurization due to leakage through the hole after removal of the previous implant, stem subsidence, increased risk of postoperative infection, periprosthetic fractures, increased risk of dislocation and prosthetic failure $[14,25]$. It has been reported that there is a statistically significant lower five and ten-year implant survival when total hip arthroplasty was done as salvage procedure compared to as primary procedure [18].

In this series, the main reasons for failure of internal fixation were cutting and backing out of screws and impingement over the acetabular walls in cases where compression screws were used due to early weight bearing and inappropriate initial fixation. A vascular necrosis of femoral head was seen in 12 out of the 15 cases of failed neck femur fractures. Secondary osteoarthritis with pain and restricted range of motions was the main indication for total hip in an acetabular fracture in our series. In this study, the average preoperative Harris hip score was 37.32 and average postoperative score at 6 months follow-up was 75.74. 17 cases (56\%) cases had a fair outcome, 9 
cases $(30 \%)$ had a good outcome and 4 cases $(14 \%)$ had a poor outcome. At the end of 1 year, 27 (90\%) of 30 patients had no pain or mild pain and 3 had moderate to severe pain. 28 (93\%) of 30 patients were able to walk without support. 27 (90\%) patients were able to climb staircase with or without support. These results are comparable to those in found in the literature $[16,17,19,26]$.

We recommend doing a complete set of investigations and a through radiographic analysis to find out the causes of failure and to rule out infection which can affect the decision making of the type of surgery. Technical challenges are expected and which include difficult dissection, excessive blood loss, and difficult implant removal with a possibility of intraoperative fractures at the previous screw holes, difficult cementing procedure. We recommend keeping a complete set for implant removal for specific previous implant and insertion of bone plugs or cementing plugs in order to avoid spilling of cement while pressurizing the femoral stem. Post-operative wound care is of utmost important to avoid infection. Apart from the operative difficulties, patients are expected to have financial and psychological burden due to multiple surgeries and longer postoperative hospital stay. It has also been reported that the salvage arthroplasty procedure itself costs more than the primary arthroplasty procedure [27]. The strength of our study includes patients of wide age group ranging from 36years to 60years. The limitations of this study include itsretrospective nature and have a relatively short average follow-up of 14 months.

\section{Conclusion}

In conclusion, despite being a technically demanding nature of the procedure, salvage total hip arthroplasty showed good durability and functional outcomes and is an effective reconstruction option for failed treatment of proximal femur fractures. The problems associated with salvage arthroplasty include difficult exposure, difficulty during cement pressurization due to leakage through the hole after removal of previous implant, stem subsidence, increased risk of postoperative infection, periprosthetic fractures, increased chance of dislocation, prosthetic failure, wound-related complications, and increased hospital stay apart from the psychological and financial burden on the patients.

\section{Conflict of Interest}

All procedures performed in studies involving human participants were in accordance with the ethical standards of the institutional and/or national research committee and with the 1964 Helsinki declaration and its later amendments or comparable ethical standards. Informed consent was obtained from all individual participants included in the study. Authors declare no conflict of interest.

\section{References}

1. Archibeck MJ, Carothers JT, Tripuraneni KR, White RE (2013) Total hip arthroplasty after failed internal fixation of proximal femoral fractures.
J Arthroplasty 28(1): 168-171.

2. Shi X, Zhou Z, Yang J, Shen B, Kang P, et al. (2015) Total Hip Arthroplasty Using Non-Modular Cementless Long-Stem Distal Fixation for Salvage of Failed Internal Fixation of Intertrochanteric Fracture. J Arthroplasty 30(11): 1999-2003.

3. Tetsunaga T, Fujiwara K, Endo H, Noda T, Tetsunaga T, et al. (2017) Total hip arthroplasty after failed treatment of proximal femur fracture. Arch Orthop Trauma Surg 137(3): 417-424.

4. Tol MCJM, van den Bekerom MPJ, Sierevelt IN, Hilverdink EF, Raaymakers ELFB, et al. (2017) Hemiarthroplasty or total hip arthroplasty for the treatment of a displaced intracapsular fracture in active elderly patients. Bone Joint J 99-B(2): 250-254.

5. Zeng X, Zhan K, Zhang L, Zeng D, Yu W, et al. (2017) Conversion to total hip arthroplasty after failed proximal femoral nail antirotations or dynamic hip screw fixations for stable intertrochanteric femur fractures: a retrospective study with a minimum follow-up of 3 years. BMC Musculoskelet Disord 18(1): 38.

6. Lee YK, Kim JT, Alkitaini AA, Kim KC, Ha YC, et al. (2016) Conversion Hip Arthroplasty in Failed Fixation of Intertrochanteric Fracture: A Propensity Score Matching Study. J Arthroplasty 32(5): 1593-1598.

7. Kyle RF, Gustilo RB, Premer RF (1979) Analysis of six hundred and twenty-two intertrochanteric hip fractures. J Bone Joint Surg Am 61(2): 216-221.

8. Haidukewych GJ, Israel TA, Berry DJ (2001) Reverse obliquity fractures of the intertrochanteric region of the femur. J Bone Joint Surg Am 83$A(5): 643-650$.

9. Kyle RF, Cabanela ME, Russell TA, Swiontkowski MF, Winquist RA, et al. (1995) Fractures of the proximal part of the femur. Instr Course Lect 44: 227-253.

10. Baumgaertner MR, Solberg BD (1997) Awareness of tip-apex distance reduces failure of fixation of trochanteric fractures of the hip. J Bone Joint Surg Br 79(6): 969-971.

11. Pennal G, Davidson J, Garside H (1980) Results of treatment of acetabular fractures. Relat Res 151: 115-123.

12. Ragnarsson B, Mjoberg B (1992) Arthrosis after surgically treated acetabular fractures. Acta Orthop Scand 63(5): 511-514.

13. Mahomed NN, Arndt DC, McGrory BJ, Harris WH (2001) The Harris hip score: Comparison of patient self-report with surgeon assessment. J Arthroplasty 16(5): 575-580.

14. Mahmoud SSS, Pearse EO, Hing CB, Smith TO (2016) Outcomes of total hip arthroplasty, as a salvage procedure, following failed internal fixation of intracapsular fractures of the femoral neck: A systematic review and meta-analysis. Bone Joint J 98-B(4): 452-460.

15. De-Yong Huang, Liang Zhang, Yi-Xin Zhou, Chun-Yu Zhang, Hui Xu, et al. (2016) Total Hip Arthroplasty Using Modular Trabecular Metal Acetabular Components for Failed Treatment of Acetabular Fractures: A Mid-term Follow-up Study. Chin Med J 129(8): 903-908.

16. Thakur RR, Deshmukh AJ, Goyal A, Ranawat AS, Rasquinha VJ, et al. (2011) Management of Failed Trochanteric Fracture Fixation With Cementless Modular Hip Arthroplasty Using a Distally Fixing Stem. J Arthroplasty 26(3): 398-403.

17. Srivastav S, Mittal V, Agarwal S. Total hip arthroplasty following failed fixation of proximal hip fractures. Indian J Orthop 42(3): 279-286.

18. Franzén H, Nilsson LT, Strömqvist B, Johnsson R, Herrlin K, et al. (1990) Secondary total hip replacement after fractures of the femoral neck. J Bone Joint Surg Br 72(5): 784-787.

19. Haidukewych GJ (2009) Salvage of failed treatment of femoral neck fractures. Instr Course Lect 58(2): 83-90. 
20. Angelini M, McKee MD, Waddell JP, Haidukewych G, Schemitsch EH, et al. (2009) Salvage of failed hip fracture fixation. J Orthop Trauma 23(6): 471-478

21. D’Arrigo C, Perugia D, Carcangiu A, Monaco E, Speranza A, et al. (2011) Hip arthroplasty for failed treatment of proximal femoral fractures. J Orthop Traumatol 34(7): 939-942.

22. Haentjens P, Casteleyn PP, Opdecam P (1994) Hip arthroplasty for failed internal fixation of intertrochanteric and subtrochanteric fractures in the elderly patient. Arch Orthop Trauma Surg 113(4): 222-227.

23. Xue D, Yu J, Zheng Q, Feng G, Li W, et al. (2017) The treatment strategies of intertrochanteric fractures nonunion: An experience of 23 nonunion patients. Injury 48(3): 708-714.

24. Broderick JM, Bruce-Brand R, Stanley E, Mulhall KJ (2013) Osteoporotic
Hip fractures: The burden of fixation failure. Scientific World Journal 2013: 515197.

25. Broderick JM, Bruce-Brand R, Stanley E, Mulhall KJ (2013) Osteoporotic Hip fractures: The burden of fixation failure. Scientific World Journal 2013: 515197.

26. Weiss RJ, Kärrholm J, Hailer NP, Beckman MO, Stark A (2012) Salvage of failed trochanteric and subtrochanteric fractures using a distally fixed, modular, uncemented hip revision stem. Acta Orthop 83(5): 488-492.

27. Zhang B, Chiu KY, Wang M (2004) Hip arthroplasty for failed internal fixation of intertrochanteric fractures. J Arthroplasty 19(3): 329-333.

28. Chin G, Wright DJ, Snir N, Schwarzkopf R (2016) Primary vs Conversion Total Hip Arthroplasty: A Cost Analysis. J Arthroplasty 31(2): 362-367.

\section{Your next submission with Juniper Publishers will reach you the below assets}

- Quality Editorial service

- Swift Peer Review

- Reprints availability

- E-prints Service

- Manuscript Podcast for convenient understanding

- Global attainment for your research

- Manuscript accessibility in different formats

( Pdf, E-pub, Full Text, Audio)

- Unceasing customer service

Track the below URL for one-step submission https://juniperpublishers.com/online-submission.php 